\title{
P-15
}

\section{Methodology for Selecting Suitable Eco-friendly Traces for Road / Railway Planning and Development that Minimizes Impacts due to Natural Disasters}

\author{
Kelum W.A.* and Bandara S.
}

\author{
Ttransportation Engineering Division, Department of Civil Engineering, University of Moratuwa, \\ Katubedda, Sri Lanka \\ *iucnkel@gmail.com
}

\begin{abstract}
Various types of natural hazards, such as floods, landslides, cyclones, storms, coastal erosion and tsunami bring catastrophic results to transportation infrastructure such as roads and railway lines. Inundation, washed off, embankment failures, structural failures, debris fallen are the major problems on encountered in road and railway sector developments. Reconstruction of these damaged infrastructures significantly impacted on natural resource, and burden to the local economy. A well planned, eco-friendly, road and railway traces that avoid possible disaster prone areas will help minimizing damages by the natural disasters. Disaster resilience could be achieved by using integrated modern technological strategies, such as satellite images, digital maps, GIS databases instead of using traditional methods, such as field visits and surveys, paper maps and library surveys, at the planning stages of roads and railways.

Development of a methodology to realize suitable traces for road and rail developments, against natural disasters, using ArcGIS (Arc map version 9.3) spatial analysis tools is presented. In general by superimposing of feature layers and its attributes, such as geomorphology, terrain, land use, areas vulnerable to inundation, landslides and cyclones, a GIS database was developed. Then, by using a systematic strategy, those features and attributes are weighted according to significance and an estimated magnitude of impacts on natural resources using available information. Using these weighted, value added data, less vulnerable traces that satisfy other environmental and engineering requirements such as minimizing relocation of people, meeting curvature and gradient limitations is developed.

The case study was carried out for a section of the proposed railway extension of Kelani Valley railway line, which is connecting Ratnapura, on its way to Hambantota, from Kottawa. By using proposed methodology, three alternative rail routes were identified. They represent minimum flood hazardous route, minimum landslide hazardous route and Eco friendly route between the proposed railway station locations Ratnapura and Nivitigala.

By changing the allocated weights of the spatial features and phenomena that represent steepness of the land, land use pattern, possibility of flooding and landslide risk areas, three alternative routes were identified. The straight line distance between Ratnapura and Nivitigala was $11 \mathrm{~km}$. The length of the three alternatives that minimizes flooding, landslides/earth slips, and maximizes eco friendliness were found to be $15.75 \mathrm{~km}, 14.55 \mathrm{~km}$ and $17.65 \mathrm{~km}$ respectively. It is proposed to identify the best alternative from the above based on the findings of the environmental impact and other assessments required for this developments.
\end{abstract}

Keywords: Natural resource, Transportation, Spatial analyses, Disasters

Proceedings of the International Forestry and Environment Symposium 2013 of the Department of Forestry

and Environmental Science, University of Sri Jayewardenepura, Sri Lanka. 